\title{
Perceived Requirements of MIS Curriculum Implementation in Bilingual Developing Countries
}

\author{
Magdy M. Kabeil \\ University of Sharjah, Sharjah, United Arab Emirates
}

kabeil@sharjah.ac.ae

Executive Summary

This paper addresses additional requirements associated with implementing a standard curriculum of Management Information Systems (MIS) in bilingual developing countries where both students and workplace users speak English as a second language. In such countries, MIS graduates are required to develop bilingual computer applications and to communicate bilingually with the anticipated users of such applications.

The additional requirements are considered from three perspectives: bilingualism technology for information system design, user bilingual communication for user involvement in system development, and student bilingual communication in the educational process. Modules of bilingualism technology are proposed for incorporating into standard MIS curricula implemented in a bilingual developing environment. The average estimated percentages of these modules represent $13.55 \%$ of the curriculum contents.

A field study was carried out in a developing country where people communicate in bilingual English/Arabic. The study measures perceptions of senior MIS students and first-year alumni about these requirements. Despite several similarities in perception of both groups, results show differences in perceived required emphasis on bilingualism technology modules in each course area. Results show also differences in perceived needs for bilingual textbooks, teaching, and assessment methods within both groups according to the type of high school education. The research findings may be applied to other bilingual developing countries especially where local languages use subsets or supersets of Arabic alphabet, such as Urdu, Persian, Kurdish, and Swahili.

Keywords: MIS, IS curriculum, IS education, bilingualism, developing countries.

\section{Introduction}

The development of "Global Information Society" is transforming nearly all business processes

Material published as part of this journal, either on-line or in print, is copyrighted by the publisher of the Journal of Information Technology Education. Permission to make digital or paper copy of part or all of these works for personal or classroom use is granted without fee provided that the copies are not made or distributed for profit or commercial advantage AND that copies 1) bear this notice in full and 2) give the full citation on the first page. It is permissible to abstract these works so long as credit is given. To copy in all other cases or to republish or to post on a server or to redistribute to lists requires specific permission and payment of a fee. Contact Editor@JITE.org to request redistribution permission. including information systems education (Lewis, 2004; WSIS, 2003). One implication of this transformation is that a new curriculum of management information system (MIS) should include new components of internationalization (or "il1n" as it is written in some literature) and should be accessible to other cultures. 
Most research on MIS curriculum internationalization focuses on enabling students with English mother tongue to deal with other cultures' requirement (Tastle \& Dumdun, 1998). It has not been possible to find published research involving enabling students from other bilingual developing countries to have efficient access to such curricula.

The main objective of this paper is to address additional requirements associated with implementing a standard MIS undergraduate curriculum in bilingual developing countries where both students and workplace users speak English as a second language. A secondary objective of the paper is to propose bilingualism technology modules for incorporating into a standard MIS curriculum implemented in a bilingual environment and to measure the perception of senior MIS students and first-year alumni about the curriculum implementation in such environment.

The second section of the paper reviews literature on research work, recent standard models, and accreditation criteria of MIS curriculum. The third section discusses bilingualism issues and its implications on MIS curriculum design. The fourth section defines the research model and the fifth section describes the research method. The sixth section reports data analysis and results and the last section concludes the paper.

\section{Relevant Studies on MIS Curriculum}

Most models of MIS curriculum tend to organize course content around technologies and methodologies (Becker, McGuire, \& Medsker ,1992; Ehie, 2002; Flood \& Moll, 1990; Granger, Schroeder, Rollier, \& Esnault 1992). Some models configure courses content according to the level of application such as operational control, management control, and strategic planning (Kroenke, 1989; Williams \& Heinrichs, 1993). Other models recommend intelligent dynamic contents that are based upon knowledge domains, pedagogic methods and student characteristics (Dara-Abrams, 2002; Siemer \& Angelides, 1998).

Despite the differences in approaches to MIS curriculum design, the common objective remains satisfying the needs of workplace users and considering characteristics of exiting students. However, little research has expanded the scope of the user needs and the student characteristics to the international level.

Granger and Schroeder (1995) believe that the effect of globalization should reverberate throughout business school undergraduate curricula. They show that although some management and finance curricula address internationalization, little if any, attention is paid to an international MIS curriculum. The available research work on MIS curriculum internationalization addresses systems problem from a global perspective as general guidelines more than specific procedures (Granger, Schroeder, Rollier, \& Esnault, 1992; Tastle \& Dumdun, 1998). Some researchers focus on the impact of socio-cultural differences on international students group work and software teams (Dafoulas \& Macaulay, 2001; Pottert, Balthazardt, \& Eldert, 2000; Rahmati, 2000; Seay 2004; Thanasankit \& Corbitt 2000; Yeo, 2000).

Professional organizations such as the Association of Computing Machinery (ACM), Association for Information Systems (AIS), Association for Information Technology Professionals (AITP), Information Resource Management Association (IRMA), and the Data Administration Managers Association (DAMA) have addressed MIS curriculum design issues by publishing standard models.

One of the most recent standard MIS curriculums is the IS 2002 developed by ACM, AIS, and AITP. The IS 2002 model places communication skills as one of the main categories of exit characteristics of MIS graduates (Gorgone, Davis, Valacich, Topi, Feinstein, \& Longenecker, 2002). An important standard MIS curriculum model is the IRMA/DAMA 2000 model (Cohen, 2000). 
The two elements that are new in this model are the emphasis on the human part of the system and the focus on information resources management.

The International Federation for Information Processing (IFIP) of the United Nations Educational, Scientific and Cultural Organization (UNISCO) has attempted to address the internationalization of Informatics curricula by publishing the Informatics Curriculum Framework for Higher Education (ICF-2000). The ICF-2000 specifies a general curriculum framework from which various curriculum implementations can be constructed according to the cultural, societal and institutional factors (Mulder \& Weert, 2000). The framework offers to institutions and countries where informatics education is still developing, the foundations from which to "leapfrog" to the front of developments. Mulder and Weert (2000, p.2) state: "It is no use to fully repeat the development process with respect to informatics education that has already taken place elsewhere. This will only slow down developments and keep institutions and countries from closing the gap. Many opportunities arise from the field of informatics and its resulting technologies."

However, curriculum recommendations of both scholars and professional organizations should be considered within the criteria of accreditation bodies. Although accreditation is over 100 years old, the accreditation of MIS programs did not materialize until 2001, when it received approval of both the Computing Sciences Accreditation Board (CSAB) and the Accreditation Board for Engineering and Technology (ABET). According to these criteria, the information systems topics in MIS undergraduate curriculum must include at least 12 semester hours of fundamental information systems material and at least 18 semester hours of hardware and software principles, modern programming languages, data management, networking and telecommunications, analysis and design, and role of information systems in organizations. The criteria require program assessment mechanisms to include soliciting inputs from students along with advice from computing professionals in industry and government (Impagliazzo \& Gorgone, 2002).

The ABET conducts reviews of MIS/IS programs located outside the US. The successful revision leads to the "Substantial Equivalency" status of the reviewed program with accredited programs in the US. Such program may not be absolutely identical in format or method of delivery to US accredited programs, but it should be comparable in program contents and educational experience (Gorgone \& Kanabar, 2002).

Despite consensus among scholars, professional organizations, and accreditation agencies on considering local culture and student characteristics, none of them explicitly addresses the bilingualism issues in MIS curriculum design where both students and workplace users speak English as a second language.

\section{Bilingualism Implications on Curriculum Design}

\section{Bilingualism Case Definition:}

Bilingualism is broadly defined as a person's ability to listen, speak, read and write in two languages with some degree of proficiency (Laws, Kilgour, \& Kasabov, 2003). There are two technical distinctions of bilingualism: compound and coordinate. Compound bilingualism represents the case of an infant with bilingual parents in a linguistically mixed marriage. Coordinate bilingualism represents the case of second language learners.

The bilingualism case of the paper deals with coordinate English/Arabic (and Arabic/English) bilingualism in UAE, where Arabic is the first language that dominates cultural, social, and local business activities. English is the second language that is used mainly for higher learning and international business activities. For the purpose of this research, English/Arabic (E/A) bilingualism is considered different from Arabic/English (A/E) bilingualism. The first means that English is 
the main language of communication process and Arabic is a supportive language for clarifications; and the second means the contrary.

Arabic is one of the five official languages of the United Nations and the mother tongue of some 200 million people in 21 countries. Other languages such as Urdu, Persian, Kurdish, and Swahili, use subsets or supersets of the Arabic alphabet, which makes it an important bilingualism case.

\section{Bilingualism Technology in MIS Applications:}

Bilingual computers are defined as "those, which have the ability to store, retrieve, be programmed in, output, and operate in two languages" (Hosni \& Kotob, 1986, p.596). A common concern of Arab countries is the Arabization of MIS applications. Arabic is a right-to-left language where letters are connected and take different written forms depending on their position in a word. Some characters have as many as four different shapes (glyphs). Arabic word processors perform more processing than those for Latin languages because previously typed character may have to change shape, depending on what is typed after it (Becker, 1987). This is further complicated by entry of Arabic numerals, which, like Latin, read from left to right. Also Arabic uses diacritics (vowel marks) over certain characters and the pronunciation of the character and the meaning of the word containing that character differ according to the diacritic imposed over it. Producing Arabic characters on a computer screen requires adding about 65 new characters to the usual Latin ASCII code. These characters usually replace some special and graphic characters of the standard ASCII code. Arabic data indexing, sorting and retrieving are different from those in Latin languages (Alawneh, Daghestani, Said, \& Shweihat, 1989).

An Arabic computer standardized code (ASMO-449) was established in 1985 under the Arab Standards and Metrology Organization (ASMO) and the Arabization Coordination Bureau. However, both organizations died of political and budgetary problems and the code has not been updated, resulting in a proliferation of many new codes and additions (Portaneri \& Amara, 1996).

Unicode character encoding system provides a unique number for every character for many of the world's languages including Arabic. More than ASCII that has 128 code points and Latin-1 (ISO8859-1) that has 256 code points; Unicode has 65536 code points that are divided into 'planes'. The range of codes assigned to the Arabic set is 0600-06FF. The Unicode set may be represented using one of three encodings (Unicode Transfer Formats): UTF-8, UTF-16, and UTF-32. The same character in the same character set encoded in the same way can be represented with a different glyph on different occasions. Unicode is required by modern standards such as XML, Java, JavaScript, CORBA 3.0, and WML. Unicode Standard, Version 3.0 is available at http://www.unicode.org.

Tayli and Al-Salamah's model (1990) of E/A bilingualism is implemented on three levels: application, operating system extensions, and input/output devices. According to a research conducted by the Kuwait Institute for Scientific Research (KISR), requirements of a bilingual (E/A) computer are classified into four main areas: input/output, programming languages, operating systems, and applications and utilities (Kotob, 1985). Example requirements of bilingual input/output are the software switching from left-to-right text to right-to-left text and vise versa, adjusting resolution for Arabic letters that have a more complex calligraphic than Latin letters, and redesigning the keyboard and the representation code to consider the number of characters in each language. Muhtaseb and Al-Shaikh (1990) propose a keyboard with transparent keys that are able of displaying any shape using LCD technology.

Internet standards are moving toward supporting HTML documents in practically every language including Arabic (Ghonaimy, 1998). The Internet standard RFC 2070, which is based on the Unicode system, supports marking-up of bi-directional text where left-to-right and right-to-left 
scripts are mixed. Also, the hypertext control protocol (HTTP) has been upgraded to support character set labeling. The character set labeling permits correct document interpretation and language negotiation, which is used at a site to provide documents in the user's language of preference (Yergeau, Nicol, Adams, \& Duerst 1997).

However, software Arabization solutions are still vendors/companies proprietary products rather than educational topics in a curriculum. Additional requirements of bilingualism technology modules should be added to the MIS curriculum for enabling graduates to serve in a bilingual environment.

\section{Bilingualism in the Educational Process:}

Bilingualism in the educational process includes languages of teaching, textbooks, and assessment mechanisms. Johnson (2000) explores the implications of language diversity by showing consequences of having different languages in school or at work. He concludes by advocating bilingual education for all people, regardless of native language.

Gardner (2001) indicates that students learn differently and individuals possess particular learning strengths and weaknesses. He defines seven types of intelligence that teachers can use to develop student's skills according to her/his learning strengths. Verbal-linguistic intelligence is the most relevant of the seven intelligence types to bilingualism issues in student-instructor communication.

Brabston, Nixon and Helms (1998) believe that textbooks should be chosen according to the reading level of the class. They reviewed several readability formulas and provide readability scores for a set of introductory MIS books. Readability score is a measure of whether writing has been geared to the reading level of its audience. Text readability has an impact on both performance level and student enrollment in a course.

After the expansion in using IT and the Internet, English became the most usable language of learning in the world as a second language (Laws, Kilgour, \& Kasabov, 2003). Because of the fast pace in information technology, among other factors, it is hard to develop local MIS course materials or textbooks in Arabic. This leads to four alternatives of using a textbook of a standard MIS curriculum in a bilingual (A/E) environment: (1) preparing students over more time period to use the same text in English as it is, (2) developing an international version of the book in simple English, (3) developing additional supplements to the book in Arabic, or (4) developing a complete Arabic translation of it. Choosing one of these alternatives is a main design factor of implementing MIS curriculum in such environment. With the evolution of custom publishing (OheneDjan \& Fernandes, 2003), it is expected that curriculum designers will have, in the near future, several bilingual versions of the same textbook with reasonable readability scores for each objective linguistic environment.

Angelo and Cross (1993) recommend guidelines for effective assessment and continuous improvement mechanisms. However, any list of assessment guidelines will only be useful to the extent of student understanding and expressing herself/himself. Bilingual assessment mechanisms may be required for accurate measurement of students' feedback in such environment.

\section{Bilingualism Requirements in MIS Topics:}

Laudon and Laudon (1991) recommend information systems topics to be addressed within three domains: technical, behavioral, and organizational. Consequently, three corresponding areas of bilingualism in information systems should be identified, each with its own reference discipline and research paradigm. An integrated plan of instruction in a bilingual developing environment 
should consider bilingualism issues in all three of these areas and effectively teach students how to apply formal theory, methods, and techniques of bilingualism within and across these domains.

MIS graduates in a bilingual developing environment should be able to develop bilingual computer applications and to communicate bilingually with the anticipated user of such applications. MIS curriculum should include suitable topics, material and procedures that enable students to meet these requirements in an effective and efficient way.

\section{Research Model}

As concluded from the last two sections, perceived requirements of implementing a standard MIS curriculum in a bilingual environment should be measured on three dimensions: bilingualism technology, user communication, and student communication. On the bilingualism technology dimension, bilingualism is considered a problem of information system design, such as bilingual user interface, bilingual data manipulation, and bilingual natural language processing. The requirements on this dimension are add-on bilingualism technology modules that enable students to develop bilingual MIS applications.

On the user communication dimension, bilingualism is considered a problem of user involvement in system development lifecycle, such as bilingual systems analysis, bilingual system documentation, and bilingual Request for Proposals (RFPs). The requirements on this dimension are bilingual methods of communication associated with the user involvement in MIS development process.

On the student communication dimension, bilingualism is considered a problem of educational process, such as the language of teaching, textbooks, and assessment mechanisms. The requirements on this dimension are bilingual methods of communication associated with the MIS educational process.

Six variables are used for measuring the perceived requirements on the three dimensions. Six hypotheses about the need for different components of bilingualism and the difference in perception of senior students and first-year alumni about these requirements are defined. Table 1 depicts the research model, measured variables, and research hypotheses. 


\begin{tabular}{|c|c|c|c|c|}
\hline \multicolumn{5}{|c|}{ Table 1: Research Model and Hypotheses } \\
\hline Problem & Dimensions & Requirements & Variables & Hypotheses \\
\hline \multirow{6}{*}{ 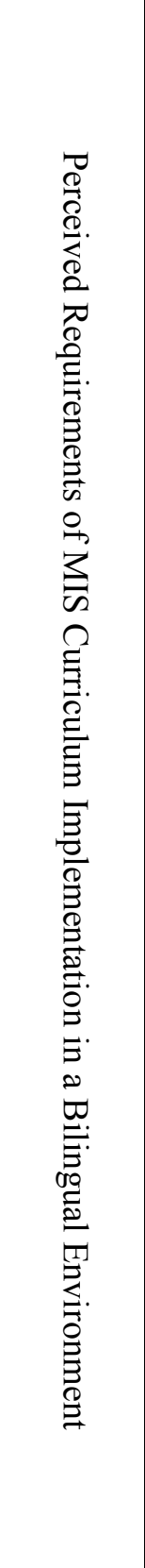 } & \multirow{2}{*}{ 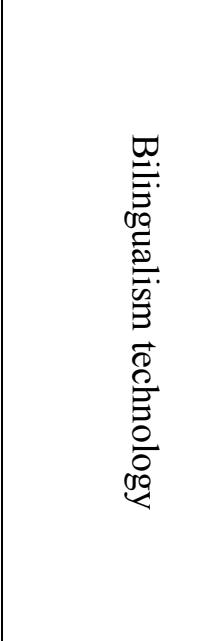 } & \multirow[b]{2}{*}{$\begin{array}{l}\text { Incorporating bi- } \\
\text { lingualism tech- } \\
\text { nology modules in } \\
\text { MIS courses }\end{array}$} & $\begin{array}{l}\text { Perceived need for } \\
\text { incorporating bilin- } \\
\text { gualism technology } \\
\text { modules in MIS } \\
\text { courses }\end{array}$ & $\begin{array}{l}\mathrm{H} 1_{0} \text { : There is no need for in- } \\
\text { corporating bilingualism tech- } \\
\text { nology modules in MIS } \\
\text { courses }\end{array}$ \\
\hline & & & \begin{tabular}{|l} 
Perceived required \\
percentage of em- \\
phasis on each pro- \\
posed bilingualism \\
technology module \\
in each MIS course \\
area
\end{tabular} & $\begin{array}{l}\mathrm{H} 2_{0}: \text { There is no significant } \\
\text { difference in perception of } \\
\text { senior student and first-year } \\
\text { alumni on the required per- } \\
\text { centage of emphasis on each } \\
\text { proposed bilingualism tech- } \\
\text { nology module in each MIS } \\
\text { course area }\end{array}$ \\
\hline & 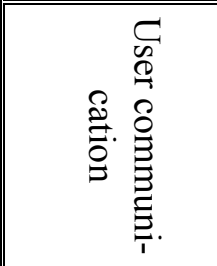 & $\begin{array}{l}\text { Using bilingual } \\
\text { methods of com- } \\
\text { munication with } \\
\text { the MIS work- } \\
\text { place users }\end{array}$ & $\begin{array}{l}\text { Perceived need for } \\
\text { using bilingual } \\
\text { methods of commu- } \\
\text { nication with work- } \\
\text { place users }\end{array}$ & $\begin{array}{l}\mathrm{H} 3_{0} \text { : There is no need for us- } \\
\text { ing bilingual methods of com- } \\
\text { munication with workplace } \\
\text { users }\end{array}$ \\
\hline & \multirow{3}{*}{ 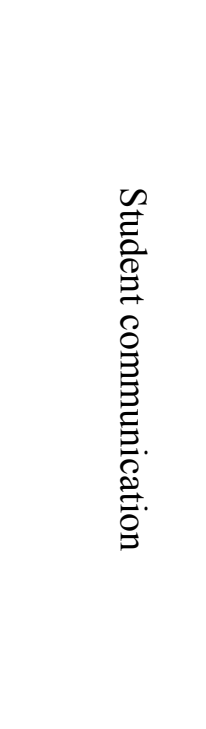 } & $\begin{array}{l}\text { Adopting bilingual } \\
\text { textbooks for MIS } \\
\text { courses }\end{array}$ & $\begin{array}{l}\text { Perceived need for } \\
\text { adopting bilingual } \\
\text { textbooks for MIS } \\
\text { courses }\end{array}$ & $\begin{array}{l}\mathrm{H} 4_{0} \text { : There is no need for } \\
\text { adopting bilingual textbooks } \\
\text { for MIS courses }\end{array}$ \\
\hline & & $\begin{array}{l}\text { Teaching MIS } \\
\text { courses in bilin- } \\
\text { gual methods }\end{array}$ & $\begin{array}{l}\text { Perceived need for } \\
\text { teaching MIS } \\
\text { courses in bilingual } \\
\text { methods }\end{array}$ & $\begin{array}{l}\mathrm{H} 5_{0} \text { : There is no need for } \\
\text { teaching MIS courses in bi- } \\
\text { lingual methods }\end{array}$ \\
\hline & & $\begin{array}{l}\text { Using MIS cur- } \\
\text { riculum assess- } \\
\text { ment mechanisms } \\
\text { prepared in bilin- } \\
\text { gual format }\end{array}$ & $\begin{array}{l}\text { Perceived need for } \\
\text { using MIS curricu- } \\
\text { lum assessment } \\
\text { mechanisms pre- } \\
\text { pared in bilingual } \\
\text { format }\end{array}$ & $\begin{array}{l}\text { H6 } 6_{0} \text { : There is no need for us- } \\
\text { ing MIS curriculum assess- } \\
\text { ment mechanisms prepared in } \\
\text { bilingual format }\end{array}$ \\
\hline
\end{tabular}




\section{Research Method}

\section{Research Environment}

The field study of this research was carried out in UAE, a typical bilingual developing environment where both students and workplace users speak English as a second language. There are seven universities locally accredited in UAE; three of them provide MIS undergraduate programs, which are the United Arab Emirates University (UAEU) at http://www.uaeu.ac.ae, the University of Sharjah (UOS) at http://www.uos.ac.ae, and the American University in Sharjah (AUS) at http://www.aus.ac.ae.

All MIS programs in the three universities adopt American curricula, use American textbooks, teach in English, and prepare for "Substantial Equivalency" status of the ABET (Kabeil, 2001). TOFEL with a minimum score of 500 is a preliminary requirement of the MIS programs at both UOS and AUS. More than $97 \%$ of students who enrolled in the three universities are native Arabic language speakers. The private high school education represents almost $30 \%$ of the local system and most of them provide American Diploma and British IGCE.

University requirements are: English and Arabic communication skills, math, statistics, and general electives. College requirements include accounting, business, management, marketing, economics, and finance courses. Despite some minor differences in courses offered in each program, all of them are within the ABET criteria.

\section{Research Approach}

Due to the emerging nature of defining additional requirements associated with implementing MIS curriculum in a bilingual environment, a research approach of three-phases was adopted. The first phase of research work was used for issue generation. The second phase was used for identifying the bilingualism technology modules proposed for each course area of the curriculum. The third phase relied on a structured method to provide quantitative data about the perceived requirements on the three dimensions, the perceived required percentage of emphasis on each bilingualism module within each course area, and the significance of difference in perception between senior students and first-year alumni.

The first phase involved a seminar followed by a "brainstorming" session with an expert group consisting of 8 MIS faculty members and 4 MIS practitioners. The discussions were guided by preliminary research questions on specific hypothetical scenarios that reflect student characteristics, market requirements of E/A bilingualism in MIS applications, language of communication between MIS practitioners and workplace users, and language of teaching, textbooks, and assessment mechanisms (Please see appendix A). The participant's comments were transcribed and content-analyzed for issue generation. The results of this phase confirmed the research model after minor changes and initiated scales development.

\section{Proposed Add-ons to MIS Curriculum in Bilingual Developing Environment}

The second phase started with defining the MIS course areas that are considered for incorporating bilingualism technology. Based upon the ABET criteria and the union of MIS courses currently offered in the country, eleven areas of MIS courses were identified with percent of emphasis on each: Principles of IT/MIS (1/18), Operating Systems (1/18), Computer Programming (2/18), Databases (2/18), Networking and Telecommunications (1/18), Internet (3/18), Security (1/18), DSS (1/18), Systems Development (3/18), Artificial Intelligence (1/18), and Internship \& Capstone 
Project (2/18). The percent of emphasis on each course area was calculated as the credit hours offered in the area divided by the total credit hours of all considered areas. Applying the bilingualism concepts to each course area of the curriculum produced a proposed add-on bilingualism technology module to the area.

A series of telephone interviews and individual meetings were conducted with MIS faculty members and practitioners for reviewing and defining the bilingualism technology modules proposed for incorporating into each course area of the curriculum. The main result of this phase was a list of add-on bilingualism technology modules that enable MIS students to develop required bilingual applications. The list was attached to the questionnaire for measuring the perceived required percentage of emphasis on each module in each course area (Please see appendix B).

\section{Measuring Research Variables and Testing Hypotheses:}

In the third phase, a survey instrument was developed and distributed with an accompanying list of proposed bilingualism technology modules of each course area. The scales were developed through the review of literature and based upon the opinions of MIS faculty and practitioners. The questionnaire consists of 27 items that cover the six variables of the research model in addition to five items for collecting demographic data from respondents. Items related to perceived requirements are measured using a Likert scale that ranged from 1 to 5. One means "Strongly Disagree" and five means "Strongly Agree." The items used for measuring percentage of emphasis on each bilingualism technology module in a course area are measured using a scale of percentage (appendix B). The questionnaire was translated to Arabic, reverse translated from Arabic to English, readjusted in two turns, and finally pilot-tested and verified using a group of eight subjects. Half of the group includes seniors and the second half alumni. Both English and Arabic versions of the questionnaire were sent to each subject to let her/him choose the most comfortable language and also to be used as a part of the subject's measured characteristics.

\section{Data Analysis and Results}

Two groups were included in the field study: MIS senior students and MIS first-year alumni working in the same environment. Mail-survey questionnaires were sent to each group. The MIS alumni group included all available students in the alumni list (212 graduates). The MIS seniors group consisted of equivalent sample of 212 students chosen randomly from class enrolment lists. With seniors' response rate of $18.4 \%$ and alumni response rate of $13.7 \%$ and after excluding 3 incomplete seniors' responses and 3 incomplete alumni's responses, 62 valid responses were considered for data processing. 
As shown in Table 2, the English high school education (American Diploma and IGCE) represents almost 30\% of the sample. Although the number of female students is almost double the number of male students, working alumni females are less than male. An interesting feature of the region is many of female students who perform better than male students in the university stay home after graduation for social reasons.

Cronbach's Alpha test was

\begin{tabular}{|c|c|c|c|}
\hline \multicolumn{4}{|c|}{ Table 2: Sample Demographics } \\
\hline High School/Gender & Students & Alumni & Subtotal \\
\hline Arabic Education (Total) & $(25)$ & (18) & (43) \\
\hline Male & 8 & 12 & 20 \\
\hline Female & 17 & 6 & 23 \\
\hline English Education (Total) & (11) & $(8)$ & (19) \\
\hline Male & 3 & 4 & 7 \\
\hline Female & 8 & 4 & 12 \\
\hline Sample Total & $(36)$ & (26) & $((62))$ \\
\hline Male & 11 & 16 & 27 \\
\hline Female & 25 & 10 & 35 \\
\hline
\end{tabular}
performed to establish the internal consistency of questionnaire scales. The values of Alpha were between 0.9492 and 0.6498. Table 3 depicts the research statistics.

\begin{tabular}{|c|c|c|c|c|c|c|c|}
\hline \multicolumn{8}{|c|}{ Table 3: Research Statistics } \\
\hline Variables & $\begin{array}{l}\text { Cronbach's al- } \\
\text { pha (Means*) }\end{array}$ & QI** & $\begin{array}{l}\text { Total } \\
\text { Mean }\end{array}$ & $\begin{array}{l}\text { Seniors } \\
\text { Mean }\end{array}$ & $\begin{array}{l}\text { Alumni } \\
\text { Mean }\end{array}$ & $\begin{array}{c}\text { Arabic } \\
\text { HSG*** } \\
\text { Mean }\end{array}$ & $\begin{array}{c}\text { English } \\
\text { HSG*** } \\
\text { Mean }\end{array}$ \\
\hline \multirow{3}{*}{$\begin{array}{l}\text { Perceived need for in- } \\
\text { corporating bilingualism } \\
\text { technology modules in } \\
\text { MIS courses }\end{array}$} & \multirow{3}{*}{$\begin{array}{l}0.8312(3.6667 / \\
3.7315 / 3.5769 / \\
3.8992 / 3.1404)\end{array}$} & 1 & 3.8871 & 4.0278 & 3.6923 & 4.2326 & 3.1053 \\
\hline & & 2 & 3.6290 & 3.6944 & 3.5385 & 3.9535 & 2.8947 \\
\hline & & 3 & 4.3548 & 4.3056 & 4.4231 & 4.5349 & 3.9474 \\
\hline \multirow{2}{*}{$\begin{array}{l}\text { Perceived need for using } \\
\text { bilingual methods of } \\
\text { communication with } \\
\text { workplace users }\end{array}$} & \multirow{2}{*}{$\begin{array}{l}0.6498(3.6694 / \\
3.7361 / 3.5769 / \\
3.9070 / 3.1316)\end{array}$} & 4 & 3.0161 & 3.1944 & 2.7692 & 3.2093 & 2.5789 \\
\hline & & 5 & 4.3226 & 4.2778 & 4.3846 & 4.6047 & 3.6842 \\
\hline \multirow{3}{*}{$\begin{array}{l}\text { Perceived need for } \\
\text { adopting bilingual text- } \\
\text { books for MIS courses }\end{array}$} & \multirow{3}{*}{$\begin{array}{l}0.7524(3.2097 / \\
3.1667 / 3.2692 / \\
3.5736 / 2.3860)\end{array}$} & 6 & 3.4194 & 3.3611 & 3.5000 & 3.8140 & 2.5263 \\
\hline & & 7 & 3.1290 & 3.0556 & 3.2308 & 3.5581 & 2.1579 \\
\hline & & 8 & 3.0806 & 3.0833 & 3.0769 & 3.3488 & 2.4737 \\
\hline \multirow{3}{*}{$\begin{array}{l}\text { Perceived need for } \\
\text { teaching MIS courses in } \\
\text { bilingual methods }\end{array}$} & \multirow{3}{*}{$\begin{array}{l}0.9180(3.2339 / \\
3.2639 / 3.1923 / \\
3.7849 / 1.9868)\end{array}$} & 9 & 3.2258 & 3.4167 & 2.9615 & 3.7674 & 2.0000 \\
\hline & & 10 & 3.2581 & 3.2500 & 3.2692 & 3.7674 & 2.1053 \\
\hline & & 11 & 3.2419 & 3.1667 & 3.3462 & 3.8372 & 1.8947 \\
\hline
\end{tabular}




\begin{tabular}{|c|c|c|c|c|c|c|c|}
\hline & & 12 & 3.2097 & 3.2222 & 3.1923 & 3.7674 & 1.9474 \\
\hline \multirow{3}{*}{$\begin{array}{l}\text { Perceived need for using } \\
\text { MIS curriculum assess- } \\
\text { ment mechanisms pre- } \\
\text { pared in bilingual for- } \\
\text { mat }\end{array}$} & \multirow{3}{*}{$\begin{array}{l}0.9492(3.2366 / \\
3.2407 / 3.2308 / \\
3.8760 / 1.7895)\end{array}$} & 13 & 3.2903 & 3.3056 & 3.2692 & 3.9767 & 1.7368 \\
\hline & & 14 & 3.1935 & 3.1667 & 3.2308 & 3.7907 & 1.8421 \\
\hline & & 15 & 3.2258 & 3.2500 & 3.1923 & 3.8605 & 1.7895 \\
\hline \multirow{11}{*}{$\begin{array}{l}\text { Perceived required per- } \\
\text { centage of emphasis on } \\
\text { each proposed bilingual- } \\
\text { ism technology module } \\
\text { in each MIS course area }\end{array}$} & \multirow{11}{*}{$\begin{array}{c}0.7971 \\
(13.55 \% / \\
10.93 \% / \\
17.18 \% / \\
14.07 \% / \\
12.38 \%)\end{array}$} & 16 & $15.00 \%$ & $14.44 \%$ & $15.77 \%$ & $17.09 \%$ & $10.26 \%$ \\
\hline & & 17 & $9.10 \%$ & $6.64 \%$ & $12.50 \%$ & $9.14 \%$ & $9.00 \%$ \\
\hline & & 18 & $10.50 \%$ & $7.92 \%$ & $14.04 \%$ & $11.23 \%$ & $8.79 \%$ \\
\hline & & 19 & $8.70 \%$ & $6.83 \%$ & $11.15 \%$ & $8.93 \%$ & $8.00 \%$ \\
\hline & & 20 & $3.60 \%$ & $2.67 \%$ & $4.85 \%$ & $3.60 \%$ & $3.53 \%$ \\
\hline & & 21 & $9.60 \%$ & $8.33 \%$ & $11.35 \%$ & $10.23 \%$ & $8.16 \%$ \\
\hline & & 22 & $3.30 \%$ & $2.28 \%$ & $4.69 \%$ & $3.37 \%$ & $3.11 \%$ \\
\hline & & 23 & $8.80 \%$ & $6.89 \%$ & $11.35 \%$ & $8.95 \%$ & $8.32 \%$ \\
\hline & & 24 & $13.40 \%$ & $10.89 \%$ & $16.92 \%$ & $13.95 \%$ & $12.21 \%$ \\
\hline & & 25 & $5.10 \%$ & $2.72 \%$ & $8.31 \%$ & $5.09 \%$ & $5.00 \%$ \\
\hline & & 26 & $15.50 \%$ & $14.31 \%$ & $17.12 \%$ & $15.93 \%$ & $14.47 \%$ \\
\hline \multicolumn{8}{|c|}{$\begin{array}{c}\text { * Means }=\text { Total Variable Mean / Students Variable Mean / Alumni Variable Mean / Arabic High } \\
\text { School Graduates Variable Mean / English High School Graduates Variable Mean }\end{array}$} \\
\hline
\end{tabular}

In addition to what is depicted in table 3, statistics show also that $17.7 \%$ of the respondents chose to allocate bilingualism technology as separate modules incorporated in each course, $21.0 \%$ chose to amalgamate all these modules in one additional course, and $61.3 \%$ chose a mixture of both ways.

A t-test was performed to see whether a null hypothesis is rejected or not. As Table 4 reflects, the computed " $\mathrm{t}$ " value of hypothesis number 2 falls within the two tails rejection range; therefore, the null hypothesis 2 is rejected at the five percent level of significance and 60 degree of freedom. The computed " $\mathrm{t}$ " values of hypotheses number 1, 3, 4, 5, and 6 fall within the one tail rejection range; therefore, the null hypotheses $1,3,4,5$, and 6 are rejected at the five percent level of significance and 61 degree of freedom. 


\begin{tabular}{|c|c|c|c|}
\hline \multicolumn{4}{|c|}{ Table 4: Test-of-Hypotheses Result } \\
\hline $\mathbf{S N}$ & Hypothesis & $\begin{array}{l}\text { Computed } \\
\text { t Value**** }\end{array}$ & $\begin{array}{c}\text { Result } \\
\text { (at .05 LOS) }\end{array}$ \\
\hline 1 & $\begin{array}{l}\mathrm{H} 1_{0} \text { : There is no need for incorporating bilingualism technol- } \\
\text { ogy modules in MIS courses }\end{array}$ & 8.447 & Rejected* \\
\hline 2 & $\begin{array}{l}\mathrm{H} 2_{0} \text { : There is no significant difference in perception of senior } \\
\text { student and first-year alumni on the required percentage of em- } \\
\text { phasis on each proposed bilingualism technology module in } \\
\text { each MIS course area }\end{array}$ & 11.916 & Rejected** \\
\hline 3 & $\begin{array}{l}\mathrm{H} 3_{0} \text { : There is no need for using bilingual methods of communi- } \\
\text { cation with workplace users }\end{array}$ & 9.710 & Rejected* \\
\hline 4 & $\begin{array}{l}\mathrm{H} 4_{0} \text { : There is no need for adopting bilingual textbooks for MIS } \\
\text { courses }\end{array}$ & 2.078 & Rejected* \\
\hline 5 & $\begin{array}{l}\mathrm{H} 5_{0} \text { : There is no need for teaching MIS courses in bilingual } \\
\text { methods }\end{array}$ & 1.990 & Rejected* \\
\hline 6 & $\begin{array}{l}\text { H6 } 6_{0} \text { : There is no need for using MIS curriculum assessment } \\
\text { mechanisms prepared in bilingual format }\end{array}$ & 1.724 & Rejected* \\
\hline \multicolumn{4}{|c|}{${ }^{*} \mathrm{H}_{0}: \mu \leq \mu 0, \mathrm{t} .05=1.671$ at 61 DOF, RR: Computed $\mathrm{t}>\mathrm{t} .05$} \\
\hline \multicolumn{4}{|c|}{${ }^{*} \mathrm{H}_{0}: \mu=\mu 0, \mathrm{t} .025=2.000$ at $60 \mathrm{DOF}, \mathrm{RR}:$ Computed $\mathrm{t}>\mathrm{t} .025$ or Computed $\mathrm{t}<-\mathrm{t} .025$} \\
\hline \multicolumn{4}{|c|}{ *** Using unequal variance model } \\
\hline
\end{tabular}

Research results show that there is a substantial need for bilingual MIS applications in the local market. This need is more in the governmental/public sector than in the private sector. However, bilingualism technology and communication are not considered in any MIS curriculum implemented in the country. Most of these types of technologies are commercial proprietary products. Bilingualism technology modules are proposed for incorporating into a standard MIS curriculum implemented in such an environment. The average estimated percentages of these modules represent $13.55 \%$ of the curriculum contents. At the same time, research statistics indicate some differences in perception of students versus first-year alumni about the required percentage of emphasis on bilingualism technology modules in each course area. In some areas such as operating systems, computer programming, databases, DSS, and artificial intelligence, differences are substantial; while in other areas such as the principles of IT/MIS, Internet, systems development, and internship and capstone project, differences are minor. This indicates that not only the level of student skills but also the student awareness of bilingualism is less than the market expectations.

On the level of user communication, the results indicate that the most required combination of languages used by developer-user communication is mainly Arabic and the technical terms in English (A/E bilingualism). However, the need for such method of communication is less in the private sector than in the governmental/public sector. 
On the level of textbooks and course material, the results indicate that the most required combination of languages to be used in textbooks and course material is mainly English with supplement notes in Arabic. However, the English language currently used in MIS textbooks reflects some of the American culture that is not clear for international students. There is a real need for textbooks that are written in simple English with examples and cases suitable for international students.

On the level of student-instructor communication, the results show that the most required combination of languages used by student-instructor communication is mainly English with explanatory sentences in Arabic (E/A bilingualism). On the level of assessment and continuous improvement, the results show that the most required language of assessment mechanisms is bilingual (E/A).

Results show also differences in perceived need for bilingual (E/A) textbooks, teaching, and assessment methods within both groups according to the type of high school education, Arabic versus English. Most students and first-year alumni who were graduated from English high schools (American Diploma or British IGCSE) do not acknowledge a high need for bilingual methods of communication in this context. This type of English high school graduate represents almost 30\% of the graduates' population.

The results of data analysis were presented to the expert group who participated in issue generation during a feedback session to confirm the author's interpretation of results. During the feedback session, two areas were suggested for further studies: the academic reward system and the multilingual textbook publishing policy. The current academic reward system follows traditional criteria, which are mainly based on teaching, research, and consulting services. A research work that explores new dimensions of the MIS academic reward system in bilingual developing environment for encouraging curriculum adaptation, teaching aids development, and bilingual textbook publishing would be a valuable addition.

Most textbook publishers target English mother-tongue students. Some large publishing companies provide translated versions of some textbooks in conventional academic fields like math and statistics. Because of the short lifecycle of MIS texts, no publisher has tried developing a new model targeting bilingual students. Suggested alternatives of a standard MIS textbook are the development of an international version of the text in simple English, additional notes in Arabic as supplements to the standard text, or complete Arabic translation of the text. Comparative analysis and readability assessment of these alternatives are valid points of research that would help developing MIS curriculum in bilingual developing countries.

\section{Conclusion}

MIS graduates in a bilingual environment should be able to develop bilingual computer applications and to communicate bilingually with the anticipated users of such applications. Implementing a standard MIS curriculum in such environments raises additional requirements that are considered in three perspectives: bilingualism technology, user communication, and student communication. In the first perspective, the additional requirements are add-on bilingualism technology modules to courses content. In the user communication perspective, the additional requirements are bilingual methods of communication associated with the user involvement in the system development. In the student communication perspective, the additional requirements are bilingual methods of communication associated with the educational process such as the language of teaching, textbooks, and assessment mechanisms.

Bilingualism technology modules are proposed for incorporating into a standard MIS curriculum implemented in such environment. The average of estimated percentages of emphasis on these modules represents $13.55 \%$ of the curriculum contents. Results of the field study show common agreement on the additional requirements with some differences in details: 
1. The need for bilingual MIS applications is more in the governmental/public sector than in the private sector.

2. The students' awareness of required bilingualism technology in general is less than the firstyear alumni.

3. Students perception about the required percentage of emphasis on bilingualism technology modules in each course area is less than the perception of first-year alumni. The difference is less in preliminary and capstone courses than others.

4. The perceived need of both students and first-year alumni who were graduated from English high schools for bilingual textbooks, teaching, and assessment methods is less than the perceived need of students and first-year alumni who graduated from Arabic high schools.

The research findings may be applied to other similar countries where local languages use subsets or supersets of Arabic alphabet, such as Urdu, Persian, Kurdish, and Swahili.

\section{References}

Alawneh, M., Daghestani, H., Said, S., \& Shweihat, K. (1989). Study of Arabization solution for microcomputers. Proceedings of the First Kuwait Computer Conference, March 27-29, 321-346.

Angelo, T. \& Cross, K. (1993). Classroom assessment techniques: A handbook for college teachers (2nd ed.). San Francisco, CA: Jossey-Bass.

Becker, J. (1987). Arabic word processing, Communication of the ACM, 30(7), 600-610.

Becker, S. A., McGuire, E. G. \& Medsker, L. R. (1992). An information systems instructional model for supporting the DPMA 1990 guidelines. Journal of Information Systems Education, 4(1), 21-25.

Brabston, M., Nixon, J. \& Helms, M. (1998). An evaluation of introductory MIS textbooks based on readability measures. Journal of Information Systems Education, Fall/Winter, 29-34.

Cohen, Eli. (2000). Curriculum model 2000 of the Information Resource Management Association and the Data Administration Managers Association. Retrieved January 5, 2003, from http://gise.org/IRMADAMA-2000.pdf

Dafoulas, G. \& Macaulay, L. (2001). Investigating cultural differences in virtual software teams. The Electronic Journal on Information Systems in Developing Countries, 7(4), 1-14.

Dara-Abrams, B. (2002). Applying multi-intelligent adaptive hypermedia to online learning. Proceedings of E-Learn 2002 Conference, Sponsored by the Association for the Advancement of Computing in Education (AACE), Montreal, Canada, October 15-19. Retrieved January 9, 2003, from http://www.brainjolt.com/docs/conclusions.pdf

Ehie, I. C. (2002). Developing a management information systems (MIS) curriculum: Perspectives from MIS practitioners. Journal of Education for Business, 77(3), January/February, 151-168.

Flood, B. \& Moll, J. (1990). The professor business: A teaching primer for faculty. Medford, NJ: Learned Information Inc.

Gardner, H. (2001). An education for the future: The foundation of science and values. Paper presented to the Royal Symposium Convened by Her Majesty, Queen Beatrix, Amsterdam, March 13.

Ghonaimy, M. (1998). Language engineering scope and basic concepts. Proceedings of the First Conference on Language Engineering, Cairo, March, 1-22.

Gorgone, J. \& Kanabar, V. (2002). The emerging IS global profession: Accreditation - The quality assurance dimension. Information Science, June, 565-570. 
Gorgone, J., Davis, G., Valacich, J., Topi, H., Feinstein, D. \& Longenecker, H. (2002). IS 2002: Model curriculum and guidelines for undergraduate programs in information systems. Retrieved December 3, 2003, from http://www.is2002.org.

Granger, M. \& Schroeder, D. (1995). Enhancing existing undergraduate information systems courses with an international emphasis. The Journal of Education for Management Information Systems. 3(1).

Granger, M., Schroeder, D., Rollier, B. \& Esnault, L. (1992). A framework for internationalization of MIS curriculum. In M. Khosrowpour (Ed.), Proceedings of the Information Resource Management Association Conference, 257-261.

Hosni, Y. \& Kotob, S. (1986). Bilinguality of microcomputers - New hardware, software and converting techniques. Computers and Industrial Engineering, 11(1-4), 596-603.

Impagliazzo, J. \& Gorgone, J. (2002). Professional accreditation of information systems programs. Communications of the Association for Information Systems (AIS), 9(3), 50-63.

Johnson, F. (2000). Speaking culturally: Language diversity in the United States. Thousand Oaks: Sage Publications.

Kabeil, M. (2001). MIS curriculum implementation in Arabic-English bilingual environment. Administrative Research Review, 13(3), 66-99.

Kotob, S. (1985). Arabic microcomputers: An assessment. Technical Report, Kuwait Institute for Scientific Research, KISR, Kuwait.

Kroenke, D. (1989). Management information systems. Santa Cruz, CA: Mitchell Publishing.

Laudon, K. \& Laudon, J. (1991). Management information systems: A contingency perspective (2nd ed.). New York, NY: Macmillan Publishing.

Laws, M., Kilgour, R., \& Kasabov, N. (2003). Modeling the emergence of bilingual acoustic clusters: a preliminary case study, Information Sciences, 156 (1-2), 85-107.

Lewis, R. (2004). Meeting report communication technology in the developing nations. Journal of Computer Assisted Learning, 20(2), 159-160.

Muhtaseb, H. \& Al-Shaikh, H. (1990). Techniques and problems of an Arabization system. Second Cambridge Conference on Bilingual Computing in Arabic and English. September 5-7, 381-399.

Mulder, F. \& Weert, T. (2000). Informatics curriculum framework for higher education (ICF-2000). International Federation for Information Processing (IFIP), United Nations Educational, Scientific and Cultural Organization (UNISCO), Paris.

Ohene-Djan, J. \& Fernandez, A. (2003). Personalizing electronic books. Journal of Digital Information, 3(4), Article No. 163.

Portaneri, F. \& Amara, F. (1996). Arabization of graphical user interfaces. In E. Del-Galdo \& J. Nielsen (Eds.), International User Interface. Hoboken, NJ: John Wiley \& Sons.

Pottert, R., Balthazardt, P., \& Eldert, K. (2000). Delivering the cross-culture virtual teamwork experience: An example with Mexican and American MBA team members. Journal of Information Systems Education, 11(3-4), 111-220.

Rahmati, N. (2000). Teaching information systems and international students: A qualitative examination of the cultural differences in computer supported group work. The Proceedings of the 15th Annual Conference of the International Academy for Information Management, December 8-10, Brisbane, Australia, 276-285.

Seay, C. (2004). Using a 'socio-cultural' approach in teaching information technology to African American students with academic difficulties. Journal of Information Technology Education, 3, 83-102.

Siemer, J. \& Angelides, M. (1998). A comprehensive method for the evaluation of complete intelligent pedagogic systems. Decision Support Systems, 22(1), 85-102. 
Tastle, W. \& Dumdun, U. (1998). Globalization issues in information systems education: Toward a collaborative multischool systems analysis experience. Journal of Information Systems Education, Winter, 19-23.

Tayli, M. \& Al-Salamah, A. (1990). Building bilingual microcomputer systems. Communications of the $A C M, 33(5), 495-504$.

Thanasankit T. \& Corbitt, B. (2000). Cultural context and its impact on requirements elicitation in Thailand. The Electronic Journal on Information Systems in Developing Countries, 1(2), 1-19.

Williams, G. \& Heinrichs, L. A. (1993). Proposed MIS curriculum modeled on Anthony's pyramid. Journal of Information Systems Education, 5(3).

WSIS. (2003). World Summit on the Information Society: Plan of Action. U. N. Document WSIS03/GENEVA/DOC/5-E, Geneva, Retrieved January 9, 2003, from http://www.itu.int/wsis

Yeo, A. (2000). Are usability assessment techniques reliable in non-western cultures? The Electronic Journal on Information Systems in Developing Countries, 3(1), 1-21.

Yergeau, F., Nicol, G., Adams, G., \& Duerst, M. (1997). Internationalization of the hypertext markup language, RFC 2070, Network Working Group, Retrieved January 9, 2003, from http://www.ietf.org/rfc/rfc2070.txt

\section{Appendix (A): Seminar Participation Form}

Based upon what have been reported in the opening presentation and according to your personal experience/judgment, please answer or mark the best choice of each item. Your input will be highly appreciated.

Preliminary Question: What percentage you suggest for each item?

$\%$ of our students speak Arabic as a $1^{\text {st }}$ language.

$\%$ of our students are graduated from Arabic schools.

$\%$ of our students expect working for Arabic environment.

$\%$ of our students want to learn developing MIS applications for Arabic-English environment.

$\%$ of our students have difficulty reading / studying the textbooks which are written in Eng-

lish because of the language.

$\%$ of our students have difficulty communicating with the instructor in English because of the language.

\section{Basic Question 1/3:}

\section{Scenario:}

- $70 \%$ of market requirements are bilingual English-Arabic MIS applications.

- $80 \%$ of students expect working for bilingual English-Arabic work places.

- The course material is prepared for developing MIS applications for an English environment.

The question: What is the best teaching strategy?

to teach students how to develop monolingual English applications and after that how to ask somebody else to transfer it to bilingual English-Arabic applications. (If it is your best choice, what percentage the student should give to the second person?), 
to prepare additional material for teaching how to transfer a monolingual English Application to a bilingual English-Arabic Application, or

to prepare material for teaching how to develop bilingual English-Arabic Applications in the first place.

Another Strategy:

\section{Basic Question 2/3:}

\section{Scenario:}

- $70 \%$ of work places communicate in Bilingual Arabic-English.

- $80 \%$ of students expect working for bilingual Arabic-English work places.

- The teaching material is prepared for keeping user involvement in developing MIS applications in English.

The question: What is the best teaching strategy?

$\square$ to teach students how to develop communication media with the user in English and after that how to ask somebody else to transfer it to bilingual Arabic-English media. (if this is your best choice, what percentage your student should give to the second person?), or

$\square$ to prepare material for teaching how to develop bilingual Arabic-English communication media with the user in the first place.

Another Strategy:

\section{Basic Question 3/3:}

\section{Scenario:}

- There is a course of MIS technology that taught in 48 contact hours.

- The textbook, teaching material, and assessment forms are written in English.

- Students speak Arabic as a $1^{\text {st }}$ language.

- Students have difficulty reading/studying/expressing in pure English.

The question: What is the best teaching strategy?

$\square$ to give the first part of the 48 hours to English instructor and to use the $2^{\text {nd }}$ part for teaching MIS subjects in English, (if this is your best choice, how many hours you give to English instructor?),

$\square$ to prepare a textbook in simple international English and to use the 48 hours for teaching MIS Technology,

$\square$ to prepare Arabic supplement of the textbook and to use the 48 hours for teaching MIS Technology, or

$\square$ Another Strategy:

\section{Please enter your personal data:}

What is your current status? 


\section{[MIS Faculty] [MIS Developer] [MIS User] [MIS Alumni] [MIS student]}

How many years have you been in this category?

- $\quad$ less than 1 ,

- from 1 to less than 2,

- from 2 to less than 3 ,

- from 3 to less than 4 , or

- more than 4 .

How many years have you been in bilingual Arabic/English environment?

- less than 1 ,

- from 1 to less than 3 ,

- $\quad$ from 3 to less than 5,

- $\quad$ from 5 to less than 7 , or

- more than 7.

What is your age group?

- less than 20,

- from 20 to less than 30,

- from 30 to less than 40,

- from 40 to less than 50, or

- more than 50. 


\section{Appendix (B): Questionnaire}

The purpose of this questionnaire is to study the English-Arabic bilingualism issues in MIS curriculum. Please take a few minutes to fill out the three parts of the following form.

PART 1: Please indicate the extent to which you agree or disagree with each of the following statements by circling one of the numbers from 1 to 5 , given that: $1=$ Strongly Disagree and $5=$ Strongly Agree.

1. More than $70 \%$ of Request for Proposals (RFP) in our region ask for bilingual English-Arabic information systems

2. Job opportunities are more available for graduates who can develop bilingual English-Arabic information systems rather than who can develop monolingual English information system

3. I believe there is a need for MIS students to learn about software English-Arabic bilingualism technologies

4. There is a need for incorporating bilingual Arabic-English methods of communication with workplace users in the private sector

5. There is a need for incorporating bilingual Arabic-English methods of communication with workplace users in the governmental/public sector

6. It is more appropriate to use MIS textbooks written in simple English $\quad \begin{array}{lllll}1 & 2 & 3 & 4 & 5\end{array}$ with supplements written in Arabic and generic cases not related to specific culture

7. It is more appropriate to use MIS textbooks that have terminology and technical statements written in English and the rest of contents written in Arabic

8. There is a need for using MIS textbooks written in English-Arabic rather than monolingual English

9. I can express my self better to my MIS instructor in English-Arabic rather than in monolingual English

10. Sometimes I can't ask questions to my MIS instructor who teaches in monolingual English because of difficulties in my English

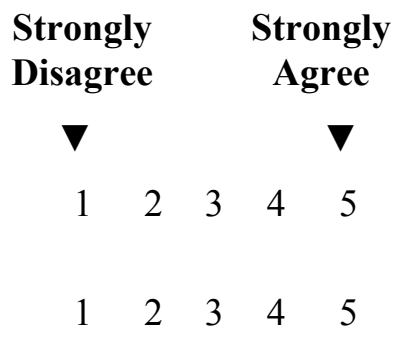

$\begin{array}{lllll}1 & 2 & 3 & 4 & 5 \\ 1 & 2 & 3 & 4 & 5\end{array}$

$\begin{array}{lllll}1 & 2 & 3 & 4 & 5 \\ 1 & 2 & 3 & 4 & 5\end{array}$

$\begin{array}{lllll}1 & 2 & 3 & 4 & 5 \\ 1 & 2 & 3 & 4 & 5 \\ 1 & 2 & 3 & 4 & 5 \\ 1 & 2 & 3 & 4 & 5 \\ 1 & 2 & 3 & 4 & 5 \\ 1 & 2 & 3 & 4 & 5 \\ 1 & 2 & 3 & 4 & 5\end{array}$

13. I cannot express my self accurately while filling-in forms of MIS cur- $\begin{array}{llllll}1 & 2 & 3 & 4 & 5\end{array}$ riculum assessment that are written in monolingual English 
14. It is more appropriate to use MIS curriculum assessment forms that are $\quad \begin{array}{llllll}1 & 2 & 3 & 4 & 5\end{array}$ written in Arabic with terminology and technical statements written in English

15. There is a need for using MIS curriculum assessment mechanisms pre- $\quad \begin{array}{llllll}1 & 2 & 3 & 4 & 5\end{array}$ pared in bilingual Arabic-English rather than monolingual English

PART 2: The statements below are related to the perceived required percentage of emphasis on English-Arabic bilingualism technology modules in each course area of MIS curriculum.

Please fill in your estimate of the need for English-Arabic bilingualism technology as a percentage of the course area contents (items 16-26) and indicate the best alternative for item number 27.

\section{MIS Course Area: Perceived Required \% of Emphasis on E/A Bilin- gualism Technology in each Course Area}

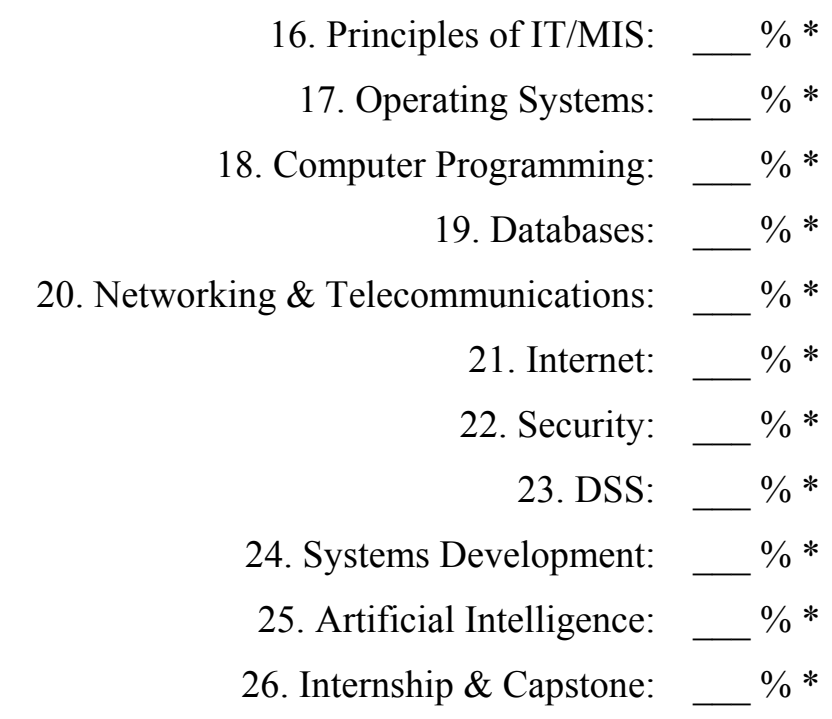

27. Best alternative of teaching bilingual-

ism: [Separate Course] [Modules in Courses] [Both Ways]

PART 3: The following are demographic items that give us an idea about the category of respondents. Please tell us a little about yourself by answering or checking one of options associated with each item.

.28. What was your percentage in the high school?

29. What type of high school was it?

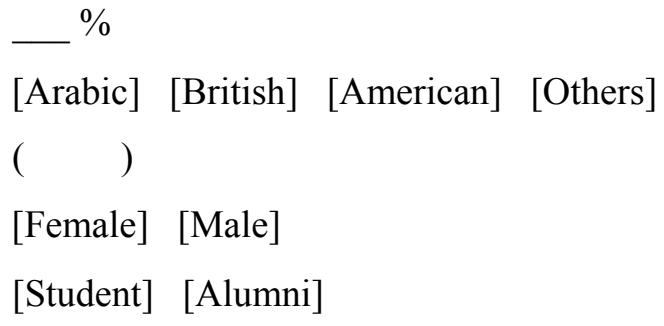
$\%$ [Arabic] [British] [American] [Others]

[Female] [Male]

[Student] [Alumni]

.30. What is your cumulative GPA (out of 4)?

.31. What is your gender?

32. Category

\section{* Next table lists proposed add-ons bilingualism technology to each MIS course area of Questionnaire Items (QI) 16-26:}




\begin{tabular}{|c|c|c|}
\hline QI & MIS Course Area & English-Arabic Bilingualism Technology \\
\hline 16 & Principles of IT/MIS & $\begin{array}{l}\text { Characteristics of Arabic language computing } \\
\text { Arabic character code set and standard encoding } \\
\text { Multi-byte standards and Unicode } \\
\text { Arabic-enabled computers } \\
\text { English-Arabic bilingual keyboarding and data entry } \\
\text { English-Arabic bilingualism in Microsoft Office (Word, Excel, Access, } \\
\text { and Power Point) } \\
\text { English-Arabic bilingualism in MIS }\end{array}$ \\
\hline 17 & Operating Systems & $\begin{array}{l}\text { Levels of supporting English-Arabic bilingualisms } \\
\text { Dual keyboard management (mapping and switching) } \\
\text { Arabic internal representation and encoding } \\
\text { Arabic character shaping and direction algorithms } \\
\text { Bilingual display management mechanisms } \\
\text { English-Arabic bilingualism in main operating systems (Windows, DOS, } \\
\text { Unix, X-Windows, and/or others) }\end{array}$ \\
\hline 18 & Computer Programming & $\begin{array}{l}\text { Arabic interface routines in programming language's library (.Net, C, } \\
\mathrm{C}++ \text {, Java) } \\
\text { Interfacing with bilingual display management mechanisms } \\
\text { Globalization classes in .NET }\end{array}$ \\
\hline 19 & Databases & $\begin{array}{l}\text { Bilingual database design and local environmental variables } \\
\text { English-Arabic bilingualism in external design } \\
\text { Creating tables with bilingual data type fields } \\
\text { English-Arabic bilingualism in conceptual design } \\
\text { Indexing, sorting and retrieving Arabic data } \\
\text { Arabic data storage representation } \\
\text { English-Arabic bilingualism in internal design } \\
\text { Arabic support in commercial DBMS (e.g. Oracle and Microsoft Access } \\
\text { and SQL Servers) }\end{array}$ \\
\hline 20 & $\begin{array}{l}\text { Networking and Tele- } \\
\text { communications }\end{array}$ & $\begin{array}{l}\text { English-Arabic bilingualism in Networking Operating Systems } \\
\text { English-Arabic bilingualism in TCP/IP } \\
\text { Introduction to bilingual Local Area Networks (LAN) } \\
\text { English-Arabic bilingualism in Telecommunications }\end{array}$ \\
\hline
\end{tabular}




\begin{tabular}{||l|l|l||}
\hline 21 & Internet & $\begin{array}{l}\text { English-Arabic bilingualism in the Internet, the World Wide Web, and e- } \\
\text { mail } \\
\text { Using DIR and LANG attributes in HTML pages } \\
\text { Bilingual WebPages design } \\
\text { Bilingual HTML programming }\end{array}$ \\
\hline \hline 22 & Security & Security of bilingual systems \\
& & Cryptographic Security for bilingual data exchange \\
\hline \hline 23 & DSS & $\begin{array}{l}\text { Bilingual interface in DSS } \\
\text { Bilingual group DSS } \\
\text { Bilingual knowledge-based subsystem } \\
\text { Bilingual data management subsystem }\end{array}$ \\
\hline \hline 24 & Systems Development & $\begin{array}{l}\text { Bilingual Systems Analysis } \\
\text { Bilingual Systems Design }\end{array}$ \\
\hline \hline 26 & Artificial Intelligence & $\begin{array}{l}\text { Arabic Speech Recognition/Synthesis } \\
\text { Arabic Characters Recognition } \\
\text { Arabic Knowledge-base Systems }\end{array}$ \\
\hline \hline
\end{tabular}

Thank you for your cooperation.

\section{Biography}

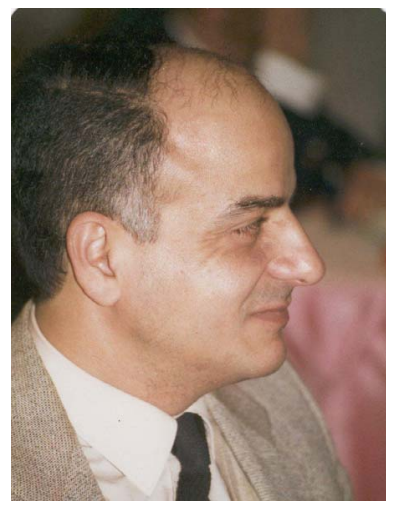

Magdy M. Kabeil is an assistant professor of MIS at the University of Sharjah, UAE, and US Fulbrighter to UC Berkeley 1995/96. He holds a PhD in Information Systems Quality Assurance from the College of Engineering, Ain Shams University, Egypt, and a MS in Operations Research and Systems Analysis from the Air Force Institute of Technology, Dayton $\mathrm{OH}$. He teaches undergraduate courses in Internet Applications, Advances in Database Applications, Systems Analysis and Design, and DSS and graduate courses in Modeling and Simulation, System Dynamics and Business Process Reengineering. In addition to authoring a textbook on DSS, Dr. Kabeil has published over 10 articles in professional publications. His research interests include DSS and IT planning, education and diffusion in developing countries. 